\title{
Regional Gestational Age and Gender-Specific Birth Weight Reference Charts and its Comparison with Existing National and International Standards: A Cross-Sectional Study
}

\author{
Ajay Prakash ${ }^{1}$ Soma Venkatesh ${ }^{1}$ Srinivasan Sadagopan ${ }^{1}$ Soundararajan Palanisamy ${ }^{1}$ \\ ${ }^{1}$ Department of Pediatrics, Mahatma Gandhi Medical College and \\ Research Institute, Pillayarkuppam, Puducherry, India \\ J Child Sci 2021;11:e306-e312. \\ Address for correspondence Soma Venkatesh, DCH, DNB, \\ Department of Pediatrics, Mahatma Gandhi Medical College and \\ Research Institute, Pillayarkuppam, Puducherry 607402, India \\ (e-mail: somavenka@gmail.com).
}

\begin{abstract}
Keywords

- newborn

- birth weight percentile

- small for gestational age

- large for gestational age
\end{abstract}

Background Growth potential is influenced by race, ethnicity, and environmental factors and assessment of growth using standardized charts is important for quality improvement initiatives in health care delivery and public health interventions of any nation.

Objective This article aims to develop regional gestational age and gender-specific reference for birth weight and to compare it with published literature.

Methodology This study was conducted in a teaching hospital in Puducherry, India and included 2,507 singleton babies. Babies with major congenital anomalies, maternal chronic illness, and nonavailability of first trimester dating scan were excluded. Detailed anthropometric measurement was done for these babies by single investigator as per established norms, their gestation- and sex-specific mean weight and weight percentiles were calculated and compared with existing data.

Results Both 10th and 90th percentiles were lower across all gestational ages compared with existing international standards. The proportion of late preterm and term small for gestational age (SGA) babies was 23\% using Fenton-2013 reference chart, $14 \%$ using Intergrowth-21 chart, and 10\% using the current study data $(p<0.0001)$. The proportion of large for gestational age (LGA) babies was $8.5 \%$, using study data. Mean birth weight of male and female term babies born to primiparae were significantly higher compared with multiparae ( $p=0.03$ and 0.02 , respectively).

Conclusion Indian babies may be overdiagnosed as SGA or underdiagnosed as LGA based on existing western standards in which our patient population is underrepresented. There is a need for gestational age-, gender-, and parity-specific regional growth charts for better characterization of anthropometric measures of Indian babies.

\section{Introduction}

Newborn anthropometry by gestational age and sex have been studied by several authors throughout the world start-

received

May 12, 2021

accepted after revision

October 8, 2021
DOI https://doi.org/

10.1055/s-0041-1740464.

ISSN 2474-5871. ing from Lubchenco et al in 1963, who were the first to introduce the intrauterine weight-based growth chart for various gestational age from the viable period. The inherent disadvantages of Lubchenco's chart, noticed over time, led to

\section{(C) 2021. The Author(s).}

This is an open access article published by Thieme under the terms of the Creative Commons Attribution License, permitting unrestricted use, distribution, and reproduction so long as the original work is properly cited. (https://creativecommons.org/licenses/by/4.0/) Georg Thieme Verlag KG, Rüdigerstraße 14, 70469 Stuttgart, Germany 
the development of Millennium cohort in 2000, Fenton Preterm Growth Chart in 2003, World Health Organization Multicentre Growth Reference Study (WHO MGRS) in 2006, Fenton 2013 charts (meta-analysis of seven cross-sectional studies including WHO study) to merge preterm growth charts with new WHO growth standards, and finally the International Growth standards by INTERGROWTH-2 $1^{\text {st }}$ Consortium. ${ }^{1,2}$ As the growth potential of the fetus is influenced by race, ethnicity, socioeconomic status, environmental factors, gestational factors, maternal nutrition, and weight gain during pregnancy apart from newborn's sex, any noted abnormal deviation of measurement in the local population from international parameters will offer a definite insight for further exploration of the role of predisposing factors and etiological factors that are likely to be operational. Available estimates for the prevalence and mortality of small-for-gestational-age babies show that these assessments are a major focus for quality improvement initiatives in health care delivery and public health interventions of any nation. The objective of this study is to develop a regional gestation and gender-specific reference chart for birth weight of newborn babies. The secondary objective was to determine the proportion of low birth weight (LBW) babies and to study the factors associated with LBW.

\section{Methodology}

This prospective cross-sectional study was conducted in a medical college hospital which serves pregnant mothers from a union territory and two adjacent districts of the neighboring state in southern part of India. All inborn singleton babies born between 28 and 42 weeks of gestational age were included in the study by convenient sampling method, between November 2014 and May 2016 after obtaining informed consent from the mother, following approval by our Institutional Human Ethics Committee. Babies born to mothers for whom dating scan was not done and mothers with known medical illness were excluded from the study. Babies with major congenital anomalies were also excluded from the study. The completed gestational age in weeks as suggested by the antenatal ultrasonography (1st trimester dating scan) was noted for all deliveries. Babies born before 37 completed weeks of gestation were considered as preterm and those born between $34^{0 / 7}$ and $36^{6 / 7}$ weeks were termed as late preterm babies as per standard definition. Basic demographic data like maternal height, socioeconomic status (based on Kuppuswamy's Socioeconomic Status Scale ${ }^{3}$, birth order, presence of pregnancy-induced hypertension (PIH), gestational diabetes mellitus (GDM), oligohydramnios, hypothyroidism, and anemia were noted. Detailed anthropometric measurements of the babies were obtained by a single observer, adequately trained in anthropometric measurements. Weight was measured by an electronic weighing scale with an accuracy to the nearest $10 \mathrm{~g}$. Head circumference was measured using a nonstretchable tape with an accuracy to the nearest $0.1 \mathrm{~cm}$. Length was measured using an infantometer with an accuracy to the nearest $0.5 \mathrm{~cm}$. Babies born with birth weight less than $2.5,1.5$, and $1 \mathrm{~kg}$ were defined as LBW, very LBW (VLBW), and extremely LBW (ELBW) babies, respectively, as per standard definition.

\section{Statistical Methods}

Descriptive data check was done, and clear-cut outliers were identified by Tukey's methodology and excluded. Skewed data for each gestational age were transformed to normal distribution by Box-Cox method. Normality of distribution was checked by Q-Q plots and Kolmogorov-Smirnov test. Proportion of preterm births, LBW, VLBW, and ELBW babies were calculated and compared with the existing national data. Mean and standard error of mean with $95 \%$ confidence interval (CI), standard deviation, and percentiles were calculated for weight for each gestational age. Generated data was compared with data from an Indian study from Christian Medical College (CMC), Vellore, India by Kumar et $\mathrm{al}^{4}$ using two-sample $z$ test. Proportion of small for gestational age (SGA) and large for gestational age (LGA) babies using our study percentile was compared with Fenton 2013 and WHO Intergrowth-21 (IG-21) standards using Pearson's chi-square test. All statistical analysis was done using Statistical Package for the Social Studies, version 21.

\section{Results}

A total of 2,507 babies were enrolled in the study after obtaining written informed consent. Of these babies, 1,304 (52\%) were male and 1,203 (48\%) were female babies. Of the total, $14(0.6 \%)$ babies were very preterm $\left(28-31^{6 / 7}\right.$ weeks), $14(0.6 \%)$ were moderate preterm $\left(32-33^{6 / 7}\right.$ weeks $)$, and 122 (4.9\%) were late preterm (34-36 $6^{6 / 7}$ weeks). First-order births constituted $57 \%(n=1,439)$ of the study population. With respect to socioeconomic status, majority belonged to middle class (59\%) and upper lower class (35\%). Of the total, 344 (14\%) of the babies were classified as LBW out of which $18 \%$ ( $5.2 \%$ of total) were VLBW and $4 \%$ (1.2\% of total) were ELBW babies. Among the LBW babies, 73 (21\%) were preterm with weight appropriate for gestational age (AGA), 15 (4\%) were early term AGA, 27 (8\%) were preterm SGA, and 229 (67\%) were term SGA. As per Fenton 2013 reference chart, 612 (24.4\%) babies in our study were SGA.

For continuous data, analysis was done with babies belonging to 34 to 40 weeks of gestation. As babies with gestational age $<34^{0 / 7}$ weeks were sparsely represented, they were excluded from analysis. - Table 1 depicts the gestation and gender-wise mean birth weight with $95 \% \mathrm{CI}$. Female babies weighed less than male babies and the difference was significant in term babies ( $p=0.34$ at 40 weeks, 0.32 at 39 weeks, and $<0.001$ at 38 weeks). No significant difference in weight was observed between the babies belonging to the two major socioeconomic status in our study, middle class and upper lower class $(p=0.2)$. Mean weight of both male and female babies born to primiparae were significantly higher than the babies born to multiparae ( $p=0.03$ and 0.02 , respectively). When stratified by gestational age, the difference was significant beyond 37 weeks of gestation. 
Table 1 Mean difference in weight between male and female babies

\begin{tabular}{|c|c|c|c|c|c|c|c|}
\hline $\mathrm{GA}$ & Gender & Mean & $95 \% \mathrm{Cl}$ & $N$ & SD & SE & Significance \\
\hline \multirow[t]{2}{*}{34} & Male & 2,215 & $2,019-2,411$ & 11 & 0.32359 & 0.09756 & \multirow[t]{2}{*}{0.241} \\
\hline & Female & 2,061 & $1,901-2,221$ & 10 & 0.25309 & 0.08003 & \\
\hline \multirow[t]{2}{*}{35} & Male & 2,223 & $2,097-2,349$ & 12 & 0.21960 & 0.06339 & \multirow[t]{2}{*}{0.783} \\
\hline & Female & 2,254 & $2,068-2,440$ & 10 & 0.29489 & 0.09325 & \\
\hline \multirow[t]{2}{*}{36} & Male & 2,561 & $2,459-2,663$ & 37 & 0.30865 & 0.05074 & \multirow[t]{2}{*}{0.312} \\
\hline & Female & 2,477 & $2,345-2,609$ & 35 & 0.39267 & 0.06637 & \\
\hline \multirow[t]{2}{*}{37} & Male & 2,891 & $2,823-2,959$ & 142 & 0.40448 & 0.03394 & \multirow[t]{2}{*}{0.284} \\
\hline & Female & 2,836 & $2,758-2,914$ & 118 & 0.42410 & 0.03904 & \\
\hline \multirow[t]{2}{*}{38} & Male & 3,097 & $3,061-3,133$ & 353 & 0.34449 & 0.01834 & \multirow[t]{2}{*}{$<0.0001$} \\
\hline & Female & 2,965 & $2,923-3,007$ & 336 & 0.39239 & 0.02141 & \\
\hline \multirow[t]{2}{*}{39} & Male & 3,113 & $3,077-3,149$ & 405 & 0.35652 & 0.01772 & \multirow[t]{2}{*}{0.032} \\
\hline & Female & 3,054 & $3,012-3,096$ & 384 & 0.40829 & 0.02084 & \\
\hline \multirow[t]{2}{*}{40} & Male & 3,201 & $3,141-3,261$ & 183 & 0.39494 & 0.02920 & \multirow[t]{2}{*}{0.034} \\
\hline & Female & 3,119 & 3,069-3169 & 181 & 0.33619 & 0.02499 & \\
\hline
\end{tabular}

Abbreviations: $\mathrm{Cl}$, confidence interval; GA, gestational age; SD, standard deviation; SE, standard error.

Majority of pregnant mothers in our study (61\%) had anemia. PIH, GDM, oligohydramnios, hypothyroidism, and short stature were identified in $2.5,3.4,5.1,4.4$, and $2.3 \%$ of pregnant mothers, respectively. Mean birth weight of babies were compared between pregnancies with and without the observed comorbidities, stratified by gestational age. Term babies born to mothers with short stature and oligohydramnios were found to be significantly lower in weight, although these subsets were poorly represented in the preterm population.

Univariate analysis using generalized linear model with gestational age, gender, parity, PIH, oligohydramnios, short stature, and anemia as predictors revealed oligohydramnios $(F=33.24, p=0.000)$ and short stature $(F=10.69, p=0.001)$ as significant predictors apart from gestational age, gender, and parity. Anemia, though present in majority, was not found to be a significant predictor. Babies with maternal oligohydramnios and short stature were excluded while estimating the percentile data.

The 10th and 90th percentiles for weight of female and male babies of our study were lower than that of Fenton 2013 and IG-21 data in all gestational ages (-Table 2). - Figs. 1 and 2 show the smoothened percentile curves and its comparison with Fenton 2013 and IG-21 standards

By Fenton 2013 reference standard, 517 out of 2,217 babies born between 34 and 40 weeks of gestation in our study (23\%) were SGA (95\% CI: $22 \%, 25 \%)$. But as per the 10 th percentile weight obtained from our study, only 227 out of these 2,217 babies (10\%) were SGA (95\% CI: $9 \%, 11 \%)$, which was significantly lesser $(p<0.0001)$. Almost an equal proportion of babies in our study were born LGA too (8.5\%) by the 90th percentile weight obtained from our data, whereas

Table 2 10th and 90th percentiles of birth weight of female and male babies in our study, WHO Intergrowth-21 Consortium Growth Standards and Fenton 2013 reference standards

\begin{tabular}{|c|c|c|c|c|c|c|c|c|c|c|c|c|}
\hline \multirow[t]{3}{*}{$G A$} & \multicolumn{6}{|l|}{ Girls } & \multicolumn{6}{|l|}{ Boys } \\
\hline & \multicolumn{3}{|c|}{ 10th percentile girls (g) } & \multicolumn{3}{|c|}{ 90th percentile girls (g) } & \multicolumn{3}{|c|}{ 10th percentile boys $(\mathrm{g})$} & \multicolumn{3}{|c|}{ 90th percentile boys $(\mathrm{g})$} \\
\hline & PS & IG-21 & F13 & PS & IG-21 & F13 & PS & IG-21 & F13 & PS & IG-21 & F13 \\
\hline 34 & 1,650 & 1,680 & 1,752 & 2,416 & 2,640 & 2,764 & 1,700 & 1,710 & 1,839 & 2,720 & 2,790 & 2,843 \\
\hline 35 & 1,793 & 1,920 & 1,991 & 2,788 & 2,890 & 3,050 & 1,860 & 1,950 & 2,079 & 2,850 & 3,030 & 3,121 \\
\hline 36 & 2,073 & 2,140 & 2,197 & 3,171 & 3,120 & 3,296 & 2,140 & 2,180 & 2,297 & 3,030 & 3,250 & 3,390 \\
\hline 37 & 2,216 & 2,330 & 2,416 & 3,360 & 3,320 & 3,532 & 2,370 & 2,380 & 2,529 & 3,420 & 3,450 & 3,660 \\
\hline 38 & 2,437 & 2,500 & 2,639 & 3,540 & 3,510 & 3,736 & 2,610 & 2,570 & 2,755 & 3,600 & 3,630 & 3,876 \\
\hline 39 & 2,471 & 2,650 & 2,807 & 3,602 & 3,660 & 3,878 & 2,650 & 2,730 & 2,925 & 3,620 & 3,790 & 4,034 \\
\hline 40 & 2,672 & 2,780 & 2,938 & 3,616 & 3,800 & 4,014 & 2,690 & 2,880 & 3,059 & 3,710 & 3,940 & 4,181 \\
\hline
\end{tabular}

Abbreviations: F13, Fenton reference standard 2013; GA, gestational age in weeks; IG-21, Intergrowth 21 standards; PS, present study. 


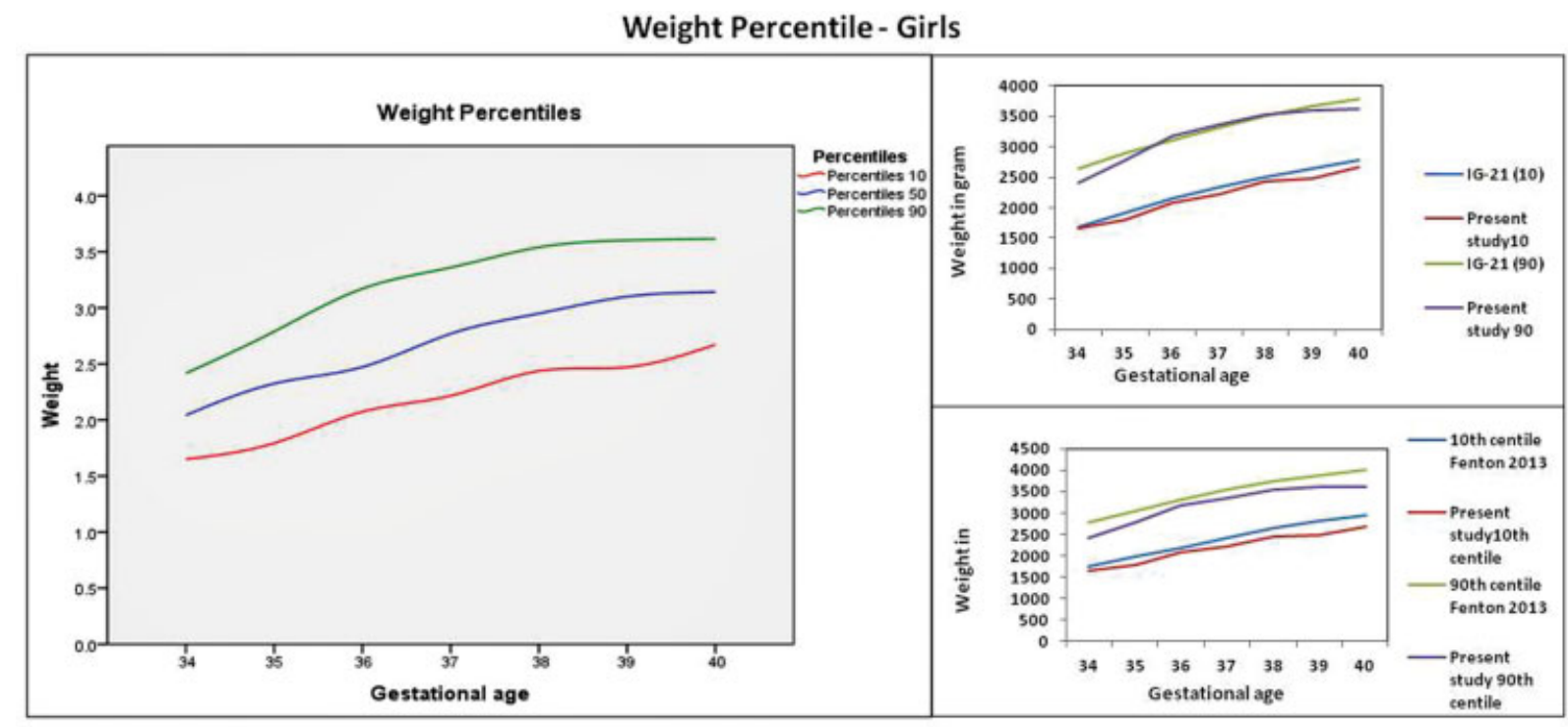

Fig. 1 Birth weight centiles (10th, 50th, 90th) of female babies in our study population and comparison with World Health Organization (WHO) Intergrowth-21 Consortium growth standards and Fenton 2013 reference standards.

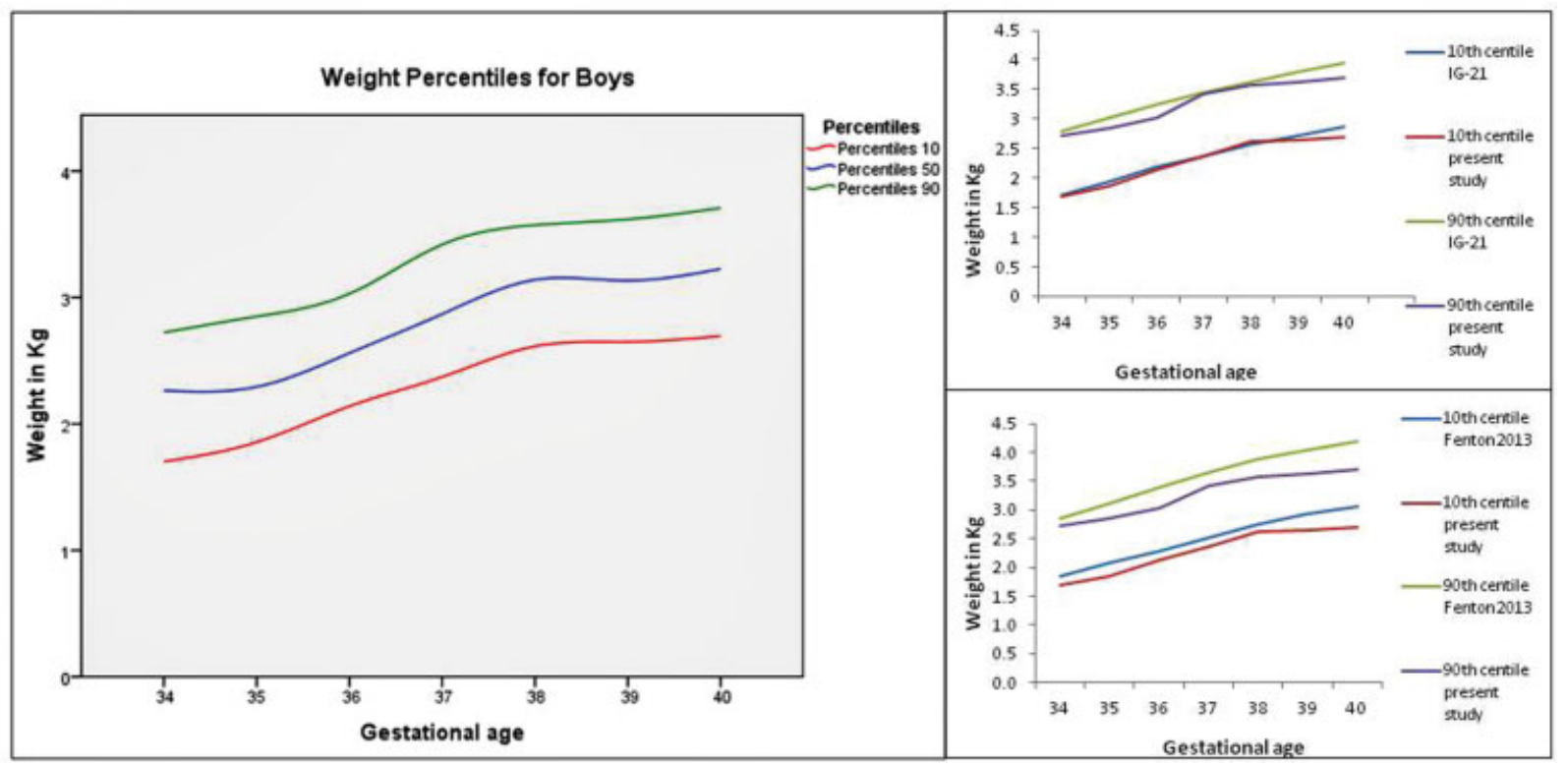

Fig. 2 Birth weight centiles (10th, 50th, 90th) of male babies in our study population and comparison with World Health Organization (WHO) Intergrowth-21 Consortium growth standards and Fenton 2013 reference standards.

only $1.5 \%$ were classified as LGA by the 90 th percentile of Fenton 2013 reference standard. WHO IG-21 postnatal growth standards, however, identified $14 \%$ of these babies as SGA which is much lesser when compared with Fenton 2013 reference standard but significantly higher than the proportion obtained based on 10th percentile of the present study data $(p<0.0001)$. IG-21 standards also identified higher proportion of LGA babies (5.5\%) in the present study population when compared with Fenton's reference standard.

The 10th and 90th percentiles for weight of female and male babies of our study, further stratified by birth order and its comparison with similar data from a retrospective study in India from $\mathrm{CMC}^{4}$ is depicted in - Fig. 3. The mean birth weight of babies born to primiparae from 37 weeks onwards is approximately 120 to $360 \mathrm{~g}$ higher for both male and female neonates in our study ( - Table 3 ) when compared with the CMC study. The number of babies born below 37 weeks of gestation, when stratified by birth order, was not found to be adequate enough for comparison.

Univariate analysis of risk factors for SGA revealed parity $(p=0.004)$ and oligohydramnios $(p<0.0001)$ as significant risk factors. A multivariable logistic regression was performed to ascertain the effects of parity, oligohydramnios, and anemia on the likelihood of a newborn baby being SGA. The logistic regression model was statistically 


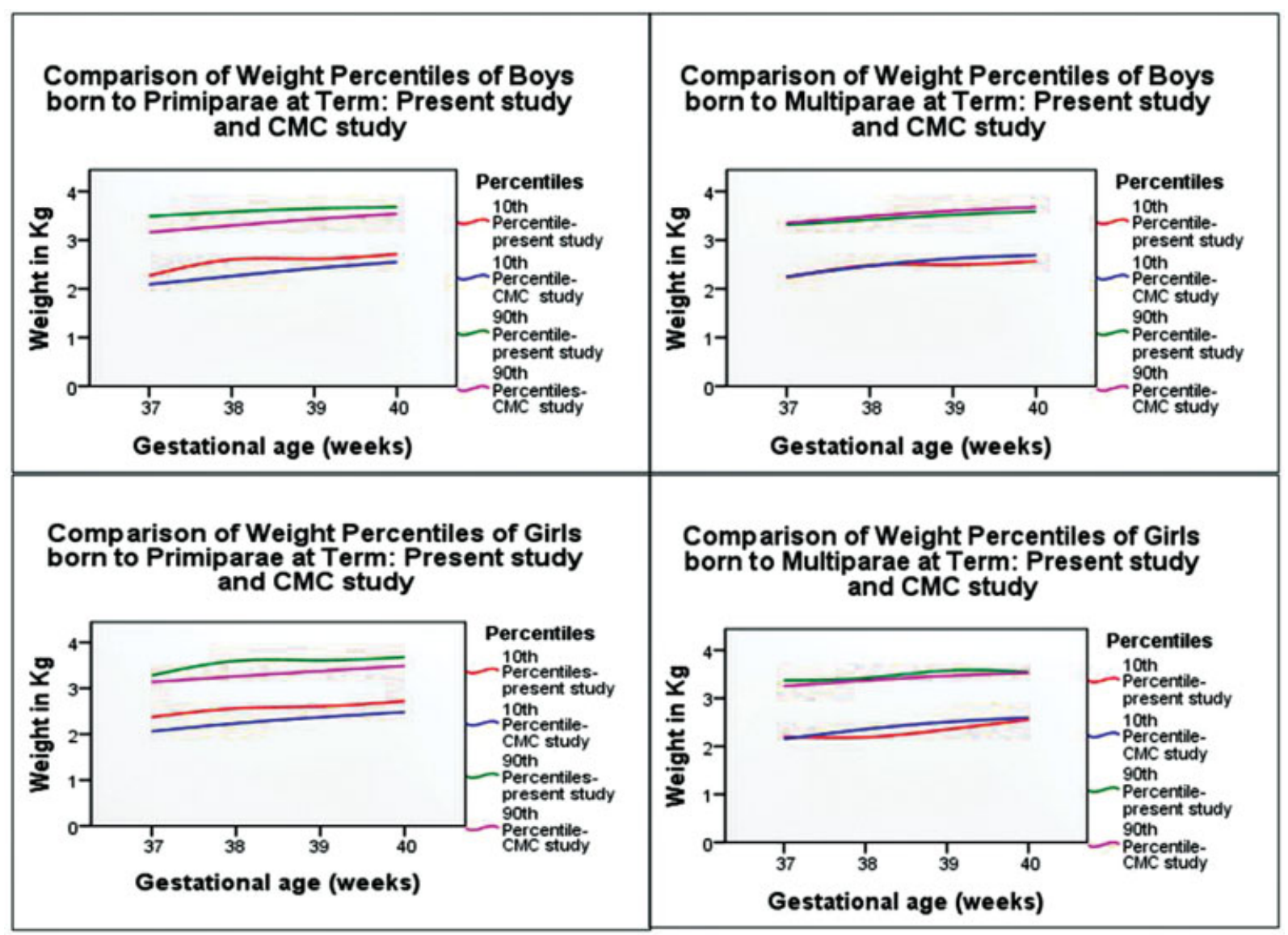

Fig. 3 Comparison of gender- and birth order-specific weight centiles between present study and Christian Medical College (CMC) study.

Table 3 Comparison of gender- and birth order-specific mean birth weight of term babies between present study and CMC Vellore study

\begin{tabular}{|c|c|c|c|c|c|c|c|}
\hline \multicolumn{4}{|c|}{ Gestational age in weeks $\rightarrow$} & 37 & 38 & 39 & 40 \\
\hline \multirow{12}{*}{$\begin{array}{l}\text { Mean birth } \\
\text { weight in gram (SD) }\end{array}$} & \multirow[t]{6}{*}{ Male } & \multirow[t]{3}{*}{ First born } & PS & $2,907(430)$ & $3130(343)$ & $3151(367)$ & 3250 (369) \\
\hline & & & CMC & $2,687(384)$ & $2774(429)$ & $2912(388)$ & $3083(391)$ \\
\hline & & & $p$-value ( $z$ test) & 0.0001 & $<0.0001$ & $<0.0001$ & $<0.0001$ \\
\hline & & \multirow[t]{3}{*}{ Later born } & PS & $2,869(366)$ & $3048(341)$ & 3060 (335) & $3138(420)$ \\
\hline & & & CMC & $2,808(453)$ & $2983(395)$ & $3119(382)$ & $3187(390)$ \\
\hline & & & $p$-value ( $z$ test) & 0.23 & 0.03 & 0.03 & 0.3 \\
\hline & \multirow[t]{6}{*}{ Female } & \multirow[t]{3}{*}{ First born } & PS & $2,843(419)$ & $3033(385)$ & 3089 (389) & $3138(330)$ \\
\hline & & & CMC & $2,637(424)$ & $2742(397)$ & $2856(384)$ & $2994(404)$ \\
\hline & & & $p$-value ( $z$ test) & 0.003 & 0.016 & $<0.0001$ & 0.0003 \\
\hline & & \multirow[t]{3}{*}{ Later born } & PS & $2,083(434)$ & $2,882(387)$ & $3,014(427)$ & $3,094(344)$ \\
\hline & & & CMC & $2,692(433)$ & 2,867 (396) & $2,981(377)$ & $3,078(366)$ \\
\hline & & & $p$-value (z test) & 0.08 & 0.64 & 0.32 & 0.4 \\
\hline
\end{tabular}

Abbreviations: CMC, Christian Medical College; PS, present study; SD, standard deviation.

Note: $p$ values in bold represent statistically significant differences.

significant, $\mathrm{X}^{2}=48.870, p<0.0001$. The model correctly classified $74.7 \%$ of the babies. Chi-square for goodnessof-fit test was 21.305 at significance level of 0.095 . Babies born to mothers with oligohydramnios are 2.5 times more likely to be SGA (95\% CI: $1.67,3.9)$. Primiparity was associated with a significant reduction in likelihood of SGA babies compared with multiparty with a risk ratio of 0.719 (95\% CI: 0.588, 0.878) (-Table 4). Also, the presence of anemia was associated with a reduction in risk of SGA babies compared with absence of anemia, which could be 
Table 4 Multivariable logistic regression analysis of independent variables predicting SGA

\begin{tabular}{|c|c|c|c|c|c|c|c|c|c|}
\hline \multirow[t]{2}{*}{ Weight category } & \multirow[t]{2}{*}{ Parameter } & \multirow[t]{2}{*}{$B$} & \multirow[t]{2}{*}{ SE } & \multirow[t]{2}{*}{ Wald } & \multirow[t]{2}{*}{ df } & \multirow[t]{2}{*}{ Significance } & \multirow[t]{2}{*}{$\operatorname{Exp}(B)$} & \multicolumn{2}{|l|}{$95 \% \mathrm{Cl}$} \\
\hline & & & & & & & & Lower & Upper \\
\hline \multirow[t]{7}{*}{ SGA } & Intercept & -0.834 & 0.098 & 72.732 & 1 & 0.000 & & & \\
\hline & Primiparity & -0.330 & 0.102 & 10.418 & 1 & 0.001 & 0.719 & 0.588 & 0.878 \\
\hline & Multiparity & $0^{\mathrm{a}}$ & . & . & 0 & . & . & . & . \\
\hline & Oligohydramnios & 0.920 & 0.216 & 18.140 & 1 & 0.000 & 2.509 & 1.667 & 3.902 \\
\hline & Adequate liquor & $0^{\mathrm{a}}$ & . & . & 0 & . & . & . & . \\
\hline & Anemia & -0.344 & 0.106 & 10.515 & 1 & 0.001 & 0.709 & 0.575 & 0.873 \\
\hline & No anemia & $0^{\mathrm{a}}$ & . & . & 0 & . & . & . & . \\
\hline
\end{tabular}

Abbreviations: AGA, appropriate for gestational age; $\mathrm{Cl}$, confidence interval; df, degrees of freedom; SE, standard error; SGA, small for gestational age.

Note: The reference category is: AGA.

${ }^{\text {a } T h i s ~ p a r a m e t e r ~ i s ~ s e t ~ t o ~ z e r o ~ b e c a u s e ~ i t ~ i s ~ r e d u n d a n t . ~}$

due to interaction of multiple predictor variables in the nonanemic group.

\section{Discussion}

The study population is a representative sample from this geographical region, predominantly belonging to middle class (59\%) and upper lower class (35\%). The proportion of male babies (52\%) was slightly higher than that of female (48\%) babies and proportion of primiparae $(57 \%)$ was higher compared with multiparae (43\%). The prevalence of LBW babies corresponds to the National Family Health Survey (NFHS)-4 data ${ }^{5}$ of Pondicherry (15\%) but lower compared with the NFHS-4 national data. The prevalence of term SGA babies (24.4\%) in our study is less compared with the national statistics as per the United Nations-Millennium Development Goals regional data, 2010 and the proportion of preterm babies are also less (6\%) compared with national statistics as per global, regional, and national estimates (13.6\%), 2014. . $^{6,7}$

The study identified pregnancies complicated by anemia, PIH, GDM, oligohydramnios, and hypothyroidism as comorbidities in $61,2.5,3.4,5.1$, and $4.4 \%$, respectively. The prevalence of anemia in our study population was slightly more than the national data (58.7\%) but less than that of Tamil Nadu (69\%), although the presence of anemia was not associated with increased risk of SGA babies in our study, the reason for which could be the presence of mild anemia in the majority. The systematic review and meta-analysis of 12 studies by the Child Health Epidemiology Reference Group states that moderate to severe maternal anemia rather than mild is associated with an SGA outcome. ${ }^{8}$

Birth order was found to be a significant predictor of birth weight in our study. Mean birth weight was found to be higher in first born term babies and multiparae were more likely to give birth to SGA babies. Few studies across the globe explored the importance of birth order and helped in the creation of gender- and birth order-specific percentile charts. ${ }^{9,10}$ Only one Indian study by Kumar et al from CMC,
Vellore, India produced gender- and birth order-specific smoothened percentile charts based on retrospective data from approximately 20,000 institutional deliveries over 15 years from 1996 to $2010 .{ }^{4}$ Since it was a retrospective study and more than a decade old, our study assumes significance as it is a prospective study and the study sample is focused on a well-defined geographic area from where no representative data exists in literature. When compared with the study by Kumar et al, ${ }^{4}$ 10th and 90th centiles of the babies born at term to multiparae in our study corresponds fairly well with that of babies born to multiparae at CMC, whereas it is significantly higher for babies born to primiparae (-Table 3$)$.

Most of the neonatal units in our country use international standards to classify neonates by birth weight into SGA, AGA, or LGA. When compared with the IG-21 Consortium chart, ${ }^{2}$ the 10th percentile of neonates in our study population were lower in all gestational ages in both the sexes except at 38 weeks for boys with an average difference of less than $100 \mathrm{~g}$. Although in female babies the 90th percentile corresponds well with the 90th percentile of IG21, in male babies we observed a wide gap (-Figs. 1 and $\mathbf{2}$ ). When compared with the Fenton 2013 reference standards, both 10th and 90th percentile was much lower in our babies and the average difference being more than $200 \mathrm{~g}$.

By Fenton 2013 reference standards, 517 out of 2,217 (23\%) babies born between 34 and 40 weeks of gestation in our study were SGA. But as per the 10th percentile weight obtained from our study, only 227 out of these 2,217 babies (10\%) were SGA. A significantly higher number of babies were identified as SGA by Fenton 2013 reference standards; however, the proportion of babies identified by IG-21 standards was only $14 \%$, which is slightly higher compared with our study. Sebastian et al in their study on 36,674 babies in a South Indian population also found that only $8.4 \%$ of the babies were SGA based on their study data, which is similar to our study. ${ }^{11}$

Almost an equal proportion of babies in our study were LGA too $(8.5 \%)$ by the 90 th percentile weight obtained from 
our data, whereas only $1.5 \%$ were LGA by the 90 th percentile of Fenton 2013 reference standards. This is also similar to the finding of Jeyaseelan et al, who found that $9.4 \%$ of a total 35,718 babies were LGA based on their study data. ${ }^{12}$ This finding leaves us with a question, whether extrapolating western standards for our babies will lead to overdiagnosis of SGA and underdiagnosis of LGA? Whether the small difference in 10th and 90th centiles of our study with the WHO IG21 data are true or by chance, needs to be evaluated since Indian babies participating in IG-21 Consortium constituted only $12 \%$ of the study population and the newborn population selected from eight different regions globally were not homogeneous. Identifying SGA babies correctly is especially important since it is an important indicator of quality of health care of a nation. Though WHO IG-21 Consortium aimed at an uniform international standard derived from prospective longitudinal study with strict inclusion criteria, we need to be cautious of such generalization. Many Indian neonatal growth charts have been developed till date, most of which are cross-sectional observations of measurements at birth at different gestational ages. Earliest among them are by Ghosh et al from Safdarjung Hospital (1971), ${ }^{13}$ Sing et al from AIMS, Delhi (1974), ${ }^{14}$ and Mathai et al from CMC, Vellore (1996). ${ }^{15}$ Kumar et al, CMC, Vellore (2013), ${ }^{4}$ even after adjusting for maternal short stature, which is an important determinant of birth size, found that both 10th and 90th percentile was lower in Indian newborn babies across all gestational ages. Hence, extrapolating western data may lead to overdiagnosis of SGA babies and underdiagnosis of LGA babies. A higher proportion of LGA babies in our study as well as in another study by Jeyaseelan et $\mathrm{al}^{12}$ is also an important finding and gives rise to a very pertinent question, whether this is related to the increasing incidence of obesity in our country.

Logistic regression analysis of risk factors associated with SGA revealed oligohydramnios and multiparity as significant risk factors (-Table 4 ). The inverse relationship of anemia and SGA found in this analysis could be due to the interaction of multiple predictor variables in the nonanemic group. The strength of this study is that it has helped us to derive a reference standard for classifying birth weight of babies born in this region. The limitations of this study include the study being that of a single center's experience with a limited sample size, lesser number of premature babies, and crosssectional study design.

To conclude, Indian babies may be overdiagnosed as SGA or underdiagnosed as LGA based on existing western standards in which our patient population is underrepresented. There is a need for gestational age, gender, as well as parityspecific regional growth charts for better characterization of anthropometric measures of Indian babies.

\section{Authors' Contributions}

A.P. performed the study with inputs on study design and study supervision by S.V., S.S., and S.P. Statistical analysis and interpretation of the data was done by S.V. The first draft of this manuscript was written by S.V. with inputs from A.P., S.S., and S.P. All authors have seen and approved the final draft.

\section{Funding}

None.

\section{Conflict of Interest}

None declared.

\section{References}

1 Fenton TR, Kim JH. A systematic review and meta-analysis to revise the Fenton growth chart for preterm infants. BMC Pediatr 2013;13:59

2 Villar J, Cheikh Ismail L, Victora CG, et al; International Fetal and Newborn Growth Consortium for the 21st Century (INTERGROWTH-21st) International standards for newborn weight, length, and head circumference by gestational age and sex: the Newborn Cross-Sectional Study of the INTERGROWTH-21st Project. Lancet 2014;384(9946):857-868

3 Sharma R. Revised Kuppuswamy's Socioeconomic Status Scale: explained and updated. Indian Pediatr 2017;54(10):867-870

4 Kumar VS, Jeyaseelan L, Sebastian T, Regi A, Mathew J, Jose R. New birth weight reference standards customised to birth order and sex of babies from South India. BMC Pregnancy Childbirth 2013; $13: 38$

5 International Institute for Population Sciences (IIPS) and ICF. National Family Health Survey (NFHS-4) 2015-16: India. Mumbai: IIPS; 2017

6 Lee AC, Katz J, Blencowe H, et al; CHERG SGA-Preterm Birth Working Group. National and regional estimates of term and preterm babies born small for gestational age in 138 low-income and middle-income countries in 2010. Lancet Glob Health 2013;1 (01):e26-e36

7 Chawanpaiboon S, Vogel JP, Moller AB, et al. Global, regional, and national estimates of levels of preterm birth in 2014: a systematic review and modelling analysis. Lancet Glob Health 2019;7(01): e37-e46

8 Kozuki N, Lee AC, Katz JChild Health Epidemiology Reference Group. Moderate to severe, but not mild, maternal anemia is associated with increased risk of small-for-gestational-age outcomes. J Nutr 2012;142(02):358-362

9 He JR, Xia HM, Liu Y, et al. A new birthweight reference in Guangzhou, southern China, and its comparison with the global reference. Arch Dis Child 2014;99(12):1091-1097

10 Bonellie S, Chalmers J, Gray R, Greer I, Jarvis S, Williams C. Centile charts for birthweight for gestational age for Scottish singleton births. BMC Pregnancy Childbirth 2008;8:5

11 Sebastian T, Yadav B, Jeyaseelan L, Vijayaselvi R, Jose R. Small for gestational age births among South Indian women: temporal trend and risk factors from 1996 to 2010. BMC Pregnancy Childbirth 2015;15:7

12 Jeyaseelan L, Yadav B, Silambarasan V, Vijayaselvi R, Jose R. Large for gestational age births among South Indian women: temporal trend and risk factors from 1996 to 2010. J Obstet Gynaecol India 2016;66(Suppl 1):42-50

13 Ghosh S, Bhargava SK, Madhavan S, Taskar AD, Bhargava V, Nigam SK. Intra-uterine growth of North Indian babies. Pediatrics 1971; 47(05):826-830

14 Singh M, Giri SK, Ramachandran K. Intrauterine growth curves of live born single babies. Indian Pediatr 1974;11(07):475-479

15 Mathai M, Jacob S, Karthikeyan NG. Birthweight standards for South Indian babies. Indian Pediatr 1996;33(03):203-209 